\title{
A população do Rio Grande de São Pedro pelos mapas populacionais de 1780 a 1810
}

\author{
Dario Scott ${ }^{\star}$
}

O objetivo deste artigo é apresentar os resultados de um exercício metodológico explorando as potencialidades e os limites dos mapas de população relativos ao Rio Grande de São Pedro, entre finais do século XVIII e início do XIX. Essa documentação, produzida por demanda da coroa portuguesa, foi elaborada para diversas capitanias e incluía, em formato de quadro ou tabela, informações relativas à população segundo sexo, condição jurídica, idade, cor/etnia. No caso do Rio Grande de São Pedro estão disponíveis sete desses “mapas”, cuja análise permite conhecer as características gerais da população dessa capitania, situada no extremo sul da América portuguesa. Nesse sentido, a partir de uma caracterização geral da documentação utilizada, buscou-se estabelecer indicadores demográficos da população naquele território na passagem do século XVIII para o século XIX, por meio das estatísticas produzidas para 1780, 1791, 1798, 1808, 1805, 1807 e 1810. Entre os resultados, destacam-se o predomínio da população branca, o desequilíbrio na razão de sexos, especialmente entre a população escrava, e a variação do peso da distribuição da população pelo território, mostrando a ocupação em direção às áreas de fronteira.

Palavras-chave: População colonial. Fontes demográficas. Demografia histórica.

*Universidade Estadual de Campinas (Unicamp), Campinas-SP, Brasil (dariostt@gmail.com). 


\section{Introdução}

O objetivo deste artigo é apresentar os resultados de um exercício metodológico explorando as potencialidades e os limites dos mapas de população relativos ao Rio Grande de São Pedro, entre finais do século XVIII e início do XIX. Essa documentação configura-se em estatísticas elaboradas, em formato de quadro ou tabela, pelo estado metropolitano português para melhor conhecer os seus domínios. Tais estatísticas foram continuamente ajustadas, para alcançar maior acuidade e padronização, por meio de inúmeros decretos e ordens régias emitidas na virada do século XVIII para o século XIX, sobretudo a partir do governo do Marquês de Pombal. ${ }^{1}$

Para auxiliar na coleta e sistematização das informações que alimentavam esses mapas de população, a coroa contava com a estrutura administrativa eclesiástica, implantada no território sob o seu domínio. À semelhança do Estado, a Igreja também tinha interesse em controlar a vida de seus fiéis. Pelas normas fixadas já desde o Concílio de Trento, exigia-se que cada paróquia tivesse um livro para assentar os registros de batizado, casamento e óbito (os assentos paroquiais), assim como a confissão e comunhão, por meio dos róis de confessados.

É importante destacar, portanto, que boa parte da informação que consta dos mapas que nos interessam analisar provém dos registros eclesiásticos mantidos pelos párocos nas respectivas freguesias, como veremos adiante. ${ }^{2}$

Conforme Paulo Matos e Paulo Silveira e Sousa (2015), admite-se que as ordens régias de $17 / 07 / 1773$ e de 21/05/1776 estavam inseridas neste processo de uniformização e melhoria da qualidade das estatísticas demográficas produzidas para a América portuguesa. O diploma real publicado em 1776 reproduzia as orientações do decreto anterior, modificava algumas das categorias utilizadas e acrescentava um caráter regular e sistemático, pois compelia os responsáveis ultramarinos a enviar anualmente os mapas estatísticos das suas administrações.

De acordo com essas instruções, as informações sobre o número de habitantes deveriam ser elaboradas respeitando as seguintes categorias:

1) Todas as crianças do sexo masculino até à idade de 7 anos completos; 2) Todos os rapazes desde a idade de 7 anos até a idade de 15; Todos os homens desde a idade de 15 anos até à idade de 60 ; 4) Todos os velhos desde a idade de 60 anos para cima com especificação particular de todos os que passam dos 90 anos; 5) Todas as crianças do sexo feminino até à idade de 7 anos completos; 6) Todos as raparigas desde a idade de 7 anos até a idade de 14; 7) Todas as mulheres desde a idade de 14 anos até à idade de

\footnotetext{
$\overline{1}$ Desde a década de 1770, o governo português colocou em prática algumas iniciativas que visavam uniformizar e qualificar as estatísticas elaboradas nas diversas partes do império, com desdobramentos que alcançaram as primeiras décadas do século XIX no Brasil.

2 Comprovando essa afirmação, veja-se o título completo do Mapa de 1791: “Mapa Geral de toda a população pertencente ao governo do continente do Rio Grande, formado pelos resumos que deram os vigários de cada uma das Freguesias do mesmo governo. Vila de São Pedro, 26 de fevereiro de 1791”. Ver Osório (2008, p. 239, nota 8).
} 
$\left.50 ;^{3} 8\right)$ Todas as velhas desde a idade de 50 anos para cima com especificação particular de todos os que passam dos 90 anos; 9) Todos os nascimentos acontecidos no ano em que tirar esta relação; 10 ) Todas as mortes acontecidas no mesmo ano. ${ }^{4}$ (MATOS; SOUSA, 2015, p. 87)

As faixas etárias indicadas evidenciam o interesse das autoridades portuguesas em conhecer a sua população em termos gerais, especialmente o contingente de súditos do sexo masculino aptos para o recrutamento militar e as mulheres em idade fértil, informação de grande importância para as políticas de população da coroa portuguesa (MATOS; SOUSA, 2015).

Para a coleta dos dados, além de acionar a estrutura da Igreja Católica (por meio dos párocos das diversas freguesias espalhadas pelos seus domínios), as ordens régias estipulavam o envolvimento dos capitães e oficiais de ordenanças.

Em artigo clássico, publicado no início da década de 1960, Dauril Alden (1963) também analisou estas fontes e chamou a atenção para as dificuldades enfrentadas na elaboração dos mapas populacionais, tais como o fato de as jurisdições eclesiásticas e administrativas nem sempre coincidirem e a resistência da população em atender às solicitações, desconfiada da eventual cobrança de impostos e recrutamento militar. 0 autor aventou a possibilidade de que os dados fornecidos pelos párocos e o posterior envolvimento de um demasiado número de pessoas na elaboração dos mapas contribuiriam para a ocorrência de uma sucessão de erros (ALDEN, 1963).

Todos esses fatores somados revelam os limites e os problemas que o uso desses mapas pode acarretar. Ainda assim, é uma fonte extremamente rica, por conta da diversidade de informações que reúne e pela cobertura e abrangência no interior do império colonial luso. Afinal, os mapas elaborados não se limitaram a coletar dados relativos apenas ao território sob o domínio de Portugal na América, ${ }^{5}$ possibilitando, dessa forma, uma infinidade de análises comparativas, que podem se expandir no âmbito de todo o império colonial luso.

\section{A capitania do Rio Grande de São Pedro}

A capitania do Rio Grande de São Pedro, localizada no extremo meridional da América portuguesa, foi alvo de intensas e recorrentes disputas entre as coroas ibéricas. Apesar dos inúmeros tratados assinados, desde o célebre Tratado de Tordesilhas (1494), não se evitaram os conflitos armados e invasões de parte a parte, que se arrastaram nos séculos seguintes, até a assinatura do Tratado de Badajoz, em 1801.

\footnotetext{
${ }_{3}^{3}$ Os autores esclarecem que o decreto de 1776 redefiniu esta categoria para o intervalo entre 14 e 40 anos.

${ }^{4}$ As medidas governamentais a respeito das estatísticas demográficas de seus domínios ocorreram simultaneamente em Portugal e na Espanha, que publicou um decreto em 10/11/1776 com objetivos semelhantes (MATOS; SOUSA, 2015). Os autores afirmam que este aspecto foi observado primeiramente por Alden (1963).

${ }^{5}$ A visita ao site Counting Colonial Populations dá uma ideia da amplitude e da cobertura temporal e espacial desses mapas de população. Ver: 〈http://colonialpopulations.fcsh.unl.pt/index.html〉.
} 
É importante destacar o interesse que a coroa portuguesa tinha na região, tendo em vista as questões geopolíticas envolvidas. Um exemplo claro foi a defesa, pelo lado português, do princípio político do uti possidetis, reconhecido pelo Tratado de Madri (1750), que garantiria a posse a quem efetivamente ocupasse as terras. Neste contexto, a coroa estimulou a instalação de imigrantes provenientes do Arquipélago da Madeira e, sobretudo, dos Açores (GRAEBIN, 2006), na região dos chamados Sete Povos das Missões, o que garantiria a posse dos seus novos territórios, fortalecendo a presença portuguesa no extremo sul da América. ${ }^{6}$ Neste contexto, a região foi sendo gradativamente ocupada, assegurando os interesses lusos na bacia do rio da Prata.

A Figura 1 mostra a capitania do Rio Grande de São Pedro em 1809, subdividida nos quatro municípios criados, que correspondem, grosso modo, às três repartições representadas nos referidos mapas. ${ }^{7}$

FIGURA 1

Mapa da capitania do Rio Grande de São Pedro - 1809

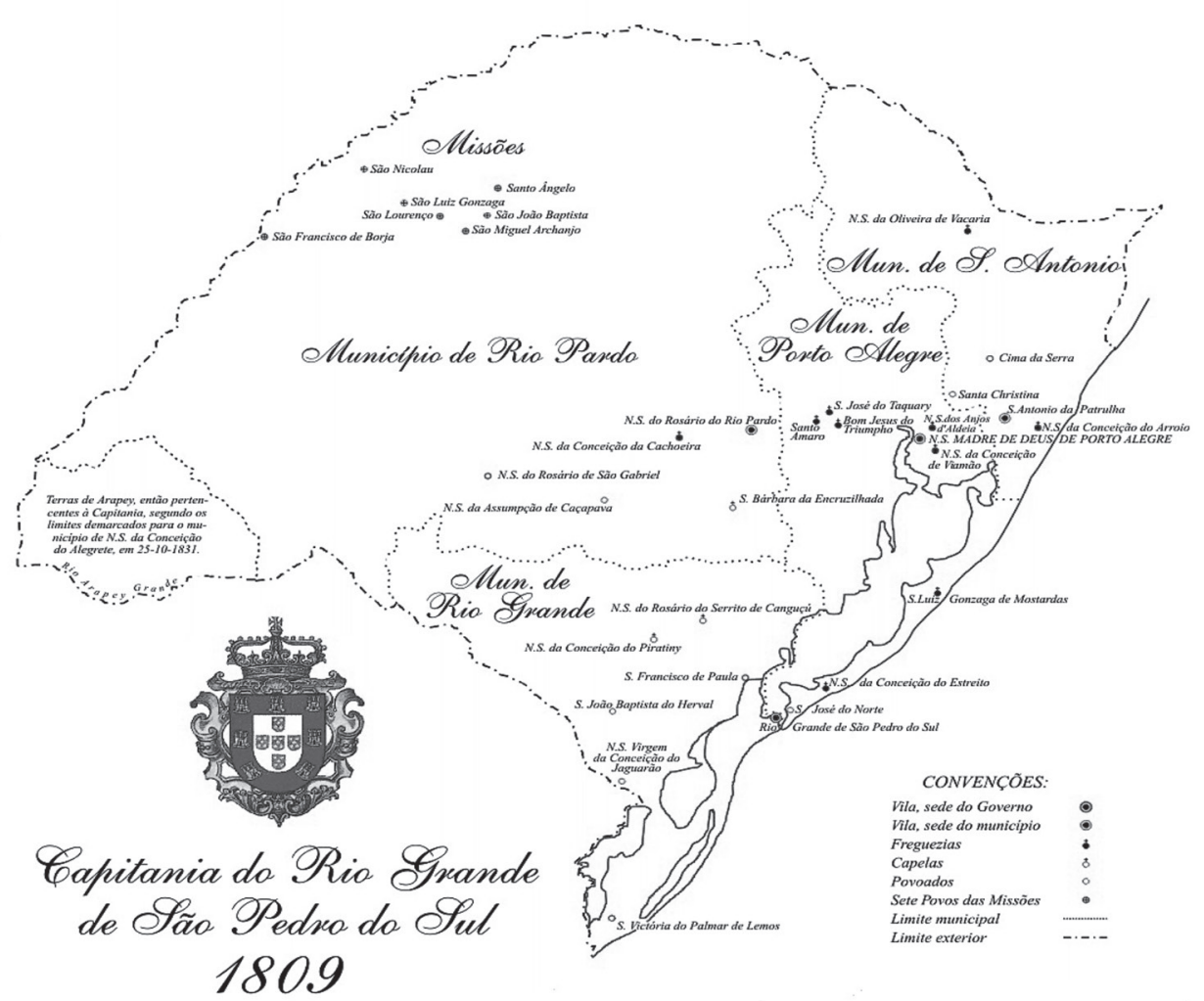

Fonte: Mapa baseado na reconstrução histórico-cartográfica, executada no Departamento Estadual de Estatística do Rio Grande do Sul, por João C. Campomar Junior, desenhista-cartógrafo, em julho de 1942, reeditado digitalmente por Sérgio Buratto em junho de 2002. Disponível em: 〈http://genealogias.org〉. Acesso em: 19 nov. 2013.

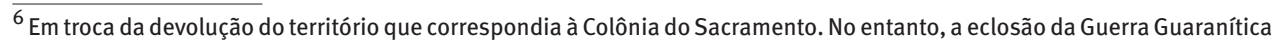
frustrou os planos relativos à instalação dos açorianos no território das missões.

${ }^{7}$ Desde que se incorpore o município de Santo Antônio com o de Porto Alegre.
} 
Nesse período a região do Rio Grande de São Pedro se desenvolveu a partir de atividades econômicas ligadas à pecuária, voltada para o mercado interno, tendo o charque como principal produto, além da venda de couros e da produção tritícola. ${ }^{8}$

Considerando-se, portanto, todas as vicissitudes da ocupação dessa área e suas atividades econômicas, interessa observar o peso que esse processo peculiar, ligado tanto às questões de disputa territorial com os espanhóis quanto aos conflitos que envolveram os nativos e à entrada de contingentes de açorianos e madeirenses, teve sobre as populações que ocuparam e povoaram a região. Esta experiência histórica diversificada estimula, assim, a exploração mais sistemática dos mapas de população disponíveis entre 1780 e 1810 , para que se examinem os desdobramentos desse processo sobre o contingente populacional que se radicou no extremo sul da América portuguesa.

\section{Explorando os mapas de população da capitania do Rio Grande de São Pedro}

Em trabalho recente, foi realizado um estudo sobre a consistência e congruências de alguns mapas populacionais, cruzando as informações dos mesmos com outras fontes produzidas pela igreja (registros paroquiais e róis de confessados) (SCOTT et al., 2015). Naquela oportunidade, os autores utilizaram o software denominado NACAOB (NAscimento, CAsamento, ÓBitos) (SCOTT; SCOTT, 2012), que faz a gestão de um banco de dados com informações provenientes de registros paroquiais, para confrontar os dados específicos da freguesia da Madre de Deus de Porto Alegre com aqueles apresentados nos mapas de população, para a mesma freguesia. 0 estudo realizado com os dados referentes àquela freguesia comprovou a estimativa feita por Alden (1963) de que a população na faixa etária entre zero e sete anos representaria perto de $11,75 \%$ do total de habitantes da localidade. Também nesse trabalho observamos os dados apresentados para os nascidos e falecidos no ano de execução do mapa. Como não há a data exata do fechamento do mapa, consideramos que as pequenas diferenças encontradas podem ser atribuídas a essa variação, uma vez que comparamos os dados dos mapas com os nascidos e falecidos entre $1^{10}$ de janeiro e 31 de dezembro do ano do respectivo mapa.

A diferença média encontrada na comparação entre os mapas de população de 1780, 1798, 1802 e 1805 e os róis de confessados foi de $15 \%$, sendo que para o mapa de 1802 a diferença observada foi de apenas $6,4 \%$. No que diz respeito à comparação dos dados do mapa de população com os registros paroquiais coletados com o NACAOB, o mapa de 1802 também foi o que apresentou a menor diferença: 1\% nos nascimentos e $2 \%$ nos óbitos. Já nos mapas de 1798 , os resultados indicam que houve subenumeração, uma vez que constatamos uma diferença de $-15 \%$ nos nascimentos

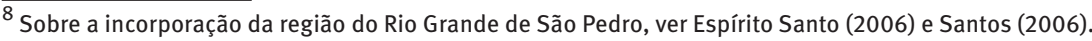


e - $50 \%$ nos óbitos. Por sua vez, para o de 1805 encontramos $-7 \%$ nos nascimentos e um sobre-registro considerável nos óbitos, chegando a $52 \%$ dos falecidos nesse ano.

No que diz respeito à documentação produzida para o Rio Grande de São Pedro, no âmbito da administração colonial, foram explorados os mapas de população relativos a $1780,1791,1798,1802,1805,1807$ e $1810 .^{9}$

Alguns desses mapas estão disponíveis no site do projeto Counting Colonial Populations, que tem por objetivo o resgate e a análise dessas estatísticas populacionais no âmbito do império português. No caso do Brasil (como um todo), os dados disponíveis correspondem ao intervalo temporal entre 1776 e $1822 .{ }^{10}$

0 projeto referido analisa as razões que levaram a coroa a elaborar este vasto conjunto de mapas e pretende disponibilizar novos dados para análise das várias políticas relativas ao império, como a ocupação do território, a gestão das populações, o exercício da fiscalidade, o recrutamento militar e o aproveitamento da mão de obra.

0 procedimento adotado para a análise dessas estatísticas partiu da identificação das variáveis contidas em cada um dos mapas utilizados. A partir daí, construímos o Quadro 1 para verificar as informações disponíveis que possibilitariam comparações e/ou aquelas que necessitariam de ajustes para viabilizar a comparabilidade entre os diferentes mapas.

Nesse sentido, o primeiro passo foi procurar reconstruir o total da população para alguns dos mapas que não dispunham da informação dos nascidos no ano, ou não computaram essa informação no total da população. Essa informação (total da população) é de extrema importância para o cálculo das taxas brutas de natalidade e mortalidade, indicadores demográficos básicos para conhecer alguns aspectos da dinâmica populacional daquele conjunto de habitantes.

O Quadro 1 apresenta a relação das informações que estão disponíveis para cada ano, bem como o total da população fornecido pelo mapa e o total corrigido, sempre procurando considerar uma distribuição uniforme para não impactar a estrutura populacional (dividida por sexo e condição jurídica).

Chama a atenção que somente os mapas de 1791 e 1810 incorporaram, no total da população, a quantidade de crianças nascidas no ano, ainda que esse número fosse somado apenas no final, não sendo distribuído entre as categorias de livres, forros, indígenas e cativos. Por esse motivo, o total da população apresentado nesses mapas não precisou ser corrigido.

\footnotetext{
${ }^{9}$ Agradeço aos colegas Paulo Teodoro Matos (UNL/CHAM) e Tarcísio Rodrigues Botelho (Departamento e Programa de Pós-graduação - História/UFMG) pela disponibilização das planilhas com os mapas populacionais utilizados neste artigo.

${ }^{10}$ Disponível em: 〈http://colonialpopulations.fcsh.unl.pt/index.html〉.
} 


\section{QUADRO 1}

Características dos mapas populacionais

Capitania do Rio Grande de São Pedro - 1780-1810

\begin{tabular}{|c|c|c|c|c|c|c|c|}
\hline $\begin{array}{l}\text { Informações contidas nos } \\
\text { mapas de população }\end{array}$ & 1780 & 1791 & 1798 & 1802 & 1805 & 1807 & 1810 \\
\hline Sexo & $x$ & $x$ & $x$ & $x$ & $x$ & $x$ & $x$ \\
\hline Cor (1) & & $x$ & $x$ & $x$ & $x$ & $x$ & $x$ \\
\hline Condição jurídica & $x$ & $x$ & $x$ & $x$ & $x$ & $x$ & $x$ \\
\hline Estado civil & $x$ & & & $x$ & $\mathrm{x}$ & & \\
\hline Nascidos no ano & & $x$ & $x$ & $x$ & $x$ & & $x$ \\
\hline Mortos no ano & & $x$ & $x$ & $x$ & $x$ & & \\
\hline Grupo de idade A (2) & & $\begin{array}{c}\mathrm{x} \\
\text { (mulheres) }\end{array}$ & & $\begin{array}{c}\mathrm{x} \\
\text { (mulheres) }\end{array}$ & & & \\
\hline Grupo de idade B (3) & & $\begin{array}{c}\mathrm{x} \\
\text { (homens) }\end{array}$ & & $\begin{array}{c}\mathrm{x} \\
\text { (homens) }\end{array}$ & $x$ & $x$ & $x$ \\
\hline Índios domésticos & & $x$ & $x$ & $x$ & $x$ & $x$ & $x$ \\
\hline Resumo & $x$ & $x$ & $x$ & $x$ & $x$ & $x$ & $x$ \\
\hline Freguesia & $x$ & & $x$ & $x$ & $x$ & $x$ & $x$ \\
\hline Repartições / Distrito & & & $x$ & & $x$ & & \\
\hline População no mapa & 17.923 & 25.034 & 31.545 & 36.721 & 41.009 & 44.340 & 52.226 \\
\hline População total corrigida & 20.309 & 25.034 & 33.286 & 39.115 & 43.008 & 46.581 & 52.226 \\
\hline
\end{tabular}

Fonte: Mapas - 1780: BNRJ, Seção de Manuscritos, 9, 4, 9 no 134; 1791: AHU_ACL_CU_019, Cx.3, doc.252, rolo 3; 1798 e 1802: AHU, Conselho Ultramarino, Rio Grande do Sul, AHU_ACL_CU_019, Cx.7, doc. 485; 1805: AHU, Conselho Ultramarino, Rio Grande do Sul, AHU_ACL_CU_019, Cx.11, doc. 669; 1807: Arquivo Nacional, Códice 808, v. 3; 1810: Arquivo Nacional, Códice 808, v. 3, folha 148. (1) É importante ressaltar que os mapas não trazem sempre explicitada a categoria cor para os brancos (que foram integrados no grupo dos livres). Essas categorias são subentendidas a partir do confronto com os grupos declarados, por exemplo, "pardo liberto ou escravo", "preto cativo ou liberto". Assume-se a categoria livre e branca, e acreditamos que seja essa a melhor qualificação para a população classificada por grupo etário, sempre lembrando que se trata de um olhar da Igreja/Estado para esses indivíduos.

(2) Grupos de idade somente da população branca feminina de 1 a 7, 7 a 15, 15 a 40 e 40 anos ou mais (em 1802 é 1 a 7, 7 a 14, 14 a 40 e 40 anos ou mais).

(3) Grupos de idade da população branca masculina até 1802 e para ambos os sexos a partir de 1805: 1 a 7, 7 a 15, 15 a 60 e 60 anos ou mais.

As correções que efetuamos nos dados apresentados pelos mapas foram as seguintes:

- como os mapas de 1780 e 1798 não apresentam a população por grupo etário, efetuamos alguns ajustes no total da população. Para 1780, que apresenta a estrutura etária distribuída nas categorias "casados", "velhos", "solteiros" e em "idade de confissão", por sexo, sabemos que o mapa não considerou os nascidos no ano (0 a 12 meses de idade), nem os menores de sete anos que é considerada a idade da “razão". Assim, estimamos as crianças de zero a sete anos para o mapa de 1780 utilizando a estimativa média apresentada por Alden (1963), que nos mostra que a população de zero a sete anos masculina era de $12,1 \%$ e a feminina de $11,4 \%$ para diversas capitanias do Brasil. Utilizamos, portanto, o valor médio de $11,75 \%$ do total da população para ajustar este mapa. No caso do mapa de 1798, o mesmo informa a população de todas as condições jurídicas (livre, escravo, forro e índio), estado civil (casados e solteiros) e todas idades agrupadas, mas, no total da população, não foi considerada a população de 0 a 1 ano (os nascidos no ano). Assim, o ajuste efetuado correspondeu somente à soma dos nascidos no ano ao total da população;

- distribuímos proporcionalmente as crianças de zero a um ano, no caso dos mapas que temos os nascidos no ano, calculamos o valor percentual de cada grupo da 
população (brancos, pardos, índios e pretos) em relação ao total da população e depois distribuímos o total de nascidos no ano aplicando o percentual calculado para cada grupo específico;

- estimamos os nascidos para os mapas de 1780 e 1807. Neste caso, encontramos a média entre os mapas que possuíam essa informação (1791, 1798, 1802, 1805 e 1810) e aplicamos o valor encontrado $(4,81 \%)$ no total da população do mapa que não dispunha dessa informação;

- estimamos as mortes no ano, efetuando um cálculo similar ao dos nascidos, e encontramos o valor médio de $2,54 \%$ do total da população, que representava os óbitos nos mapas que possuíam essa informação (1791, 1798, 1802 e 1805), e então aplicamos esse percentual aos mapas de 1780, 1807 e 1810;

- objetivando padronizar a informação por distrito, ao longo dos 30 anos estudados, distribuímos o total da população de 1791 pelo valor médio proporcional encontrado nos outros mapas e agrupamos por distrito todos os mapas pela estrutura apresentada nos mapas de 1798 e 1805.

Todos esses ajustes foram necessários para poder elaborar a Tabela 7, que reúne as informações de todos os anos analisados, com a ressalva de que os valores por distrito para 1791 são estimados.

Como podemos verificar na Tabela 1, no período analisado, a população escrava na capitania do Rio Grande de São Pedro representava, em média, pouco mais de $32 \%$ da população residente, mostrando a importância dos escravos nessa região. 0 ano de 1798 apresentou o maior percentual de escravos na capitania: $36,7 \%$ do total da população e esse percentual foi decrescendo até chegar aos $29,5 \%$ em 1810 . No sentido inverso, os homens livres passaram de 31,2\% em 1798 para 36,1\% em 1810. Essa inversão mostra uma tendência de diminuição dos cativos do sexo masculino.

TABELA 1

Distribuição da população, por condição jurídica Capitania do Rio Grande de São Pedro - 1780-1810

\begin{tabular}{lccccccc}
\hline Anos & População & $\begin{array}{c}\text { Homens } \\
\text { livres (\%) }\end{array}$ & $\begin{array}{c}\text { Mulheres } \\
\text { livres (\%) }\end{array}$ & $\begin{array}{c}\text { Escravos } \\
(\%)\end{array}$ & $\begin{array}{c}\text { Escravas } \\
(\%)\end{array}$ & $\begin{array}{c}\text { Total de } \\
\text { livres (\%) }\end{array}$ & $\begin{array}{c}\text { Total de } \\
\text { escravos (\%) }\end{array}$ \\
\hline $1780(1)$ & 20.309 & 37,5 & 34,0 & 18,0 & 10,5 & 71,5 & 28,5 \\
1791 & 25.034 & 33,7 & 32,3 & 21,8 & 12,3 & 65,9 & 34,1 \\
1798 & 33.286 & 31,2 & 32,1 & 23,5 & 13,2 & 63,3 & 36,7 \\
1802 & 39.115 & 33,2 & 31,5 & 22,3 & 13,0 & 64,7 & 35,3 \\
1805 & 43.008 & 34,7 & 31,7 & 20,7 & 12,9 & 66,4 & 33,6 \\
1807 & 46.581 & 35,9 & 33,8 & 19,5 & 10,9 & 69,6 & 30,4 \\
1810 & 52.226 & 36,1 & 34,4 & 18,4 & 11,1 & 70,5 & 29,5 \\
\hline
\end{tabular}

Fonte: Mapas - 1780: BNRJ, Seção de Manuscritos, 9, 4, 9 no 134; 1791: AHU_ACL_CU_019, Cx.3, doc.252, rolo 3; 1798 e 1802: AHU, Conselho Ultramarino, Rio Grande do Sul, AHU_ACL_CU_019, Cx.7, doc. 485; 1805: AHU, Conselho Ultramarino, Rio Grande do Sul, AHU_ACL_CU_019, Cx.11, doc. 669; 1807: Arquivo Nacional, Códice 808, v. 3; 1810: Arquivo Nacional, Códice 808, v. 3 , folha 148 .

(1) Total ajustado conforme índice proposto por Alden (1963). 
TABELA 2

Distribuição da população, por sexo, segundo grupos etários e condição jurídica Capitania do Rio Grande de São Pedro - 1791-1810

\begin{tabular}{|c|c|c|c|c|c|c|c|c|c|c|}
\hline \multirow{3}{*}{$\begin{array}{c}\text { Grupos } \\
\text { etários e } \\
\text { condição } \\
\text { jurídica }\end{array}$} & \multirow{2}{*}{\multicolumn{2}{|c|}{$1791(1)$}} & \multirow{2}{*}{\multicolumn{2}{|c|}{$1802(2)$}} & \multicolumn{6}{|c|}{ Em porcentagem } \\
\hline & & & & & & 305 & & 307 & & 310 \\
\hline & Homens & Mulheres & Homens & Mulheres & Homens & Mulheres & Homens & Mulheres & Homens & Mulheres \\
\hline $0-1$ ano & 1,6 & 1,5 & 1,7 & 1,6 & 1,4 & 1,3 & 1,5 & 1,4 & 1,6 & 1,5 \\
\hline $1-7$ anos & 6,4 & 5,9 & 7,4 & 6,8 & 8,8 & 7,6 & 9,2 & 7,9 & 8,5 & 7,6 \\
\hline $7-15$ anos & 6,1 & 5,6 & 5,3 & 5,6 & 6,3 & 6,4 & 7,0 & 6,9 & 7,5 & 7,1 \\
\hline $15-60$ anos & 14,5 & 11,9 & 11,9 & 9,8 & 11,5 & 9,1 & 12,0 & 9,9 & 12,1 & 10,7 \\
\hline 60 anos ou + & 2,3 & 4,3 & 2,2 & 2,8 & 2,2 & 2,8 & 2,0 & 3,3 & 2,0 & 3,1 \\
\hline Índios & 1,6 & 1,7 & 1,7 & 1,8 & 1,5 & 1,4 & 1,1 & 1,2 & 1,3 & 1,3 \\
\hline Forros & 1,2 & 1,4 & 3,0 & 3,1 & 2,9 & 3,2 & 3,0 & 3,2 & 3,1 & 3,1 \\
\hline Escravos & 21,8 & 12,3 & 22,3 & 13,0 & 20,7 & 12,9 & 19,5 & 10,9 & 18,4 & 11,1 \\
\hline Total & 55,5 & 44,5 & 55,5 & 44,5 & 55,4 & 44,6 & 55,3 & 44,7 & 54,5 & 45,5 \\
\hline
\end{tabular}

Fonte: Mapas - 1780: BNRJ, Seção de Manuscritos, 9, 4, 9 nํ134; 1791: AHU_ACL_CU_019, Cx.3, doc.252, rolo 3; 1798 e 1802: AHU, Conselho Ultramarino, Rio Grande do Sul, AHU_ACL_CU_019, Cx.7, doc. 485; 1805 : AHU, Conselho Ultramarino, Rio Grande do Sul, AHU_ACL_CU_019, Cx.11, doc. 669; 1807: Arquivo Nacional, Códice 808, v. 3; 1810: Arquivo Nacional, Códice 808, v. 3, folha 148.

(1) Grupo de idade da população branca feminina de 1 a 7, 7 a 15, 15 a 40 e 40 ou mais anos.

(2) Grupo de idade da população branca feminina de 1 a 7, 7 a 14, 14 a 40 e 40 ou mais anos.

Em relação à distribuição da população por grupo etário e condição jurídica (índio, ${ }^{11}$ forro e escravo), os mapas só apresentam a informação de idade para a população "livre e branca" nos anos de 1791, 1802, 1805, 1807 e 1810. Acrescente-se ainda que, nos mapas relativos a 1791 e 1802, a distribuição das mulheres, por grupo etário, difere da dos homens, conforme pode ser visto nas notas da Tabela 2. Chama a atenção que a proporção entre homens e mulheres, no quadro geral, permanece praticamente inalterada durante esses 30 anos. Podemos confirmar esse dado por meio da razão de sexo entre 1780 e 1810, apresentada na Tabela 3.

TABELA 3

Razão de sexo da população, por condição jurídica

Capitania do Rio Grande de São Pedro - 1780-1810

\begin{tabular}{cccc}
\hline \multirow{2}{*}{ Anos } & \multicolumn{3}{c}{ Razão de sexo (1) } \\
\cline { 2 - 4 } & Livres & Escravos & Total \\
\hline 1780 & 110 & 171 & 125 \\
1791 & 104 & 178 & 125 \\
1798 & 97 & 178 & 121 \\
1802 & 106 & 171 & 125 \\
1805 & 109 & 160 & 124 \\
1807 & 106 & 178 & 124 \\
1810 & 105 & 166 & 120 \\
\hline
\end{tabular}

Fonte: Mapas - 1780: BNRJ, Seção de Manuscritos, 9, 4, 9 no 134; 1791: AHU_ACL_CU_019, Cx.3, doc.252, rolo 3; 1798 e 1802: AHU, Conselho Ultramarino, Rio Grande do Sul, AHU_ACL_CU_019, Cx.7, doc. 485; 1805: AHU, Conselho Ultramarino, Rio Grande do Sul, AHU_ACL_CU_019, Cx.11, doc. 669; 1807: Arquivo Nacional, Códice 808, v. 3; 1810: Arquivo Nacional, Códice 808, v. 3, folha 148.

(1) Número de homens por cada 100 mulheres.

\footnotetext{
${ }^{11}$ Essa categoria “índio" assim foi arrolada nos mapas, sem a discriminação da condição jurídica. São considerados uma categoria a parte, contabilizados separadamente.
} 
Na Tabela 3 fica evidente o diferencial da razão de sexo encontrado entre a população livre e a escrava na capitania do Rio Grande de São Pedro, mostrando a importância dos homens para mão de obra na época. Verificamos ainda que a mão de obra escrava era majoritariamente preta, ou seja, os pardos representavam algo em torno de $10 \%$ da mão de obra escrava nessa região (Tabela 4). Essa distribuição é bem diferente da encontrada, por exemplo, no mapa da capitania do Rio Grande do Norte, onde os escravos representavam entre $19 \%$ e $15 \%$ da população no período de 1801 a 1805 e, desses, 25\% eram pardos (MATOS et al., 2016).

O Gráfico 1 e a Tabela 4 apresentam a distribuição da população de 1791 a 1810, por sexo, cor e condição jurídica. Os dados relativos a 1780 não foram incluídos, pois a classificação da população “livre branca” em grupos etários estava dividida em: meninos(as) de confissão; solteiros(as); casados(as); velhos(as).

\section{GRÁFICO 1}

Distribuição da população, por sexo, cor/etnia e condição jurídica Capitania do Rio Grande de São Pedro - 1791-1810

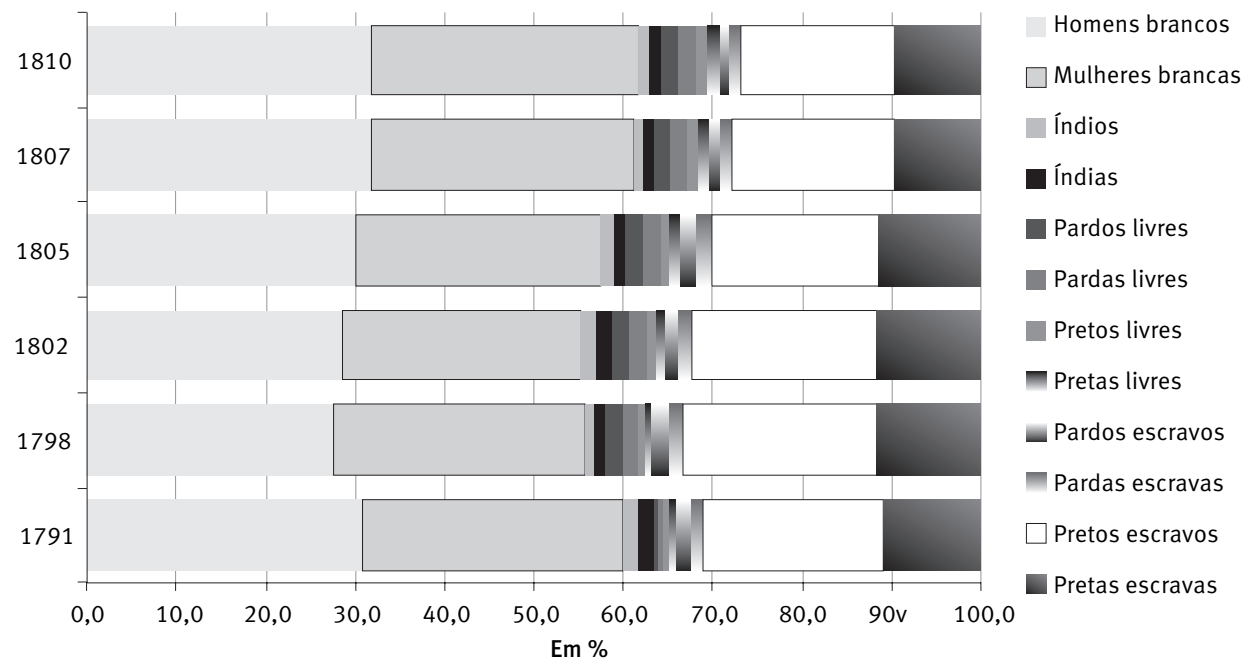

Fonte: Mapas - 1791: AHU_ACL_CU_019, Cx.3, doc.252, rolo 3; 1798 e 1802: AHU, Conselho Ultramarino, Rio Grande do Sul, AHU_ACL_CU_019, Cx.7, doc. 485; 1805: AHU, Conselho Ultramarino, Rio Grande do Sul, AHU_ACL_CU_019, Cx.11, doc. 669; 1807: Arquivo Nacional, Códice 808, v. 3; 1810: Arquivo Nacional, Códice 808, v. 3, folha 148.

A partir dos mapas também pudemos calcular as taxas brutas de natalidade e mortalidade apresentadas na Tabela 5. Cabe ressaltar que os valores informados para natalidade e mortalidade para 1780 e 1807 e para a mortalidade em 1810 são estimativas aproximadas das médias encontradas nos outros mapas de população. Deve-se considerar também que os assentos de óbito infantil normalmente apresentam sub-registro, principalmente entre os escravos.

Calculando as taxas brutas de natalidade e mortalidade com os dados dos mapas de população, chegamos aos resultados apresentados na Tabela 5. Fica difícil comparar essas taxas com outros trabalhos, pois muitos deles referem-se às altas taxas de natalidade e 
mortalidade, mas não apresentam as taxas brutas. Por exemplo, Marcílio (2000) apresenta as taxas de natalidade e mortalidade somente para mulheres livres da capitania de São Paulo, sendo a TBN igual a 53,7 nascidas por mil e a TBM igual a 42,0 por mil, em 1798. Como nosso cálculo utilizou a população total, a taxa bruta de mortalidade foi afetada pelo sub-registro de óbito infantil. Também podemos verificar essa dificuldade, que foi apontada no estudo de Sergio Nadalin (2004). No entanto, Stuart Schwartz (1988), em seu clássico trabalho Segredos internos, reúne uma série de estudos para várias sociedades escravistas na América, entre os séculos XVII e XVIII, apontando dados que podem servir de comparação para os resultados apresentados aqui. Selecionamos aqueles que dizem respeito ao conjunto da população para algumas localidades brasileiras (Tabela 6).

TABELA 4

Distribuição da população, segundo sexo, cor/etnia e condição jurídica Capitania do Rio Grande de São Pedro - 1791-1810

\begin{tabular}{lrrrrrr}
\multicolumn{1}{c}{ Sexo, cor e condição jurídica } & $\mathbf{1 7 9 1}$ & $\mathbf{1 7 9 8}$ & $\mathbf{1 8 0 2}$ & $\mathbf{1 8 0 5}$ & $\mathbf{1 8 0 7}$ & $\mathbf{1 8 1 0}$ \\
\hline Homens brancos & 30,9 & 27,5 & 28,5 & 30,2 & 31,7 & 31,7 \\
Mulheres brancas & 29,1 & 28,2 & 26,6 & 27,2 & 29,4 & 30,0 \\
Índios & 1,6 & 1,1 & 1,7 & 1,5 & 1,1 & 1,3 \\
Índias & 1,7 & 1,2 & 1,8 & 1,4 & 1,2 & 1,3 \\
Pardos livres & 0,5 & 1,9 & 2,1 & 2,0 & 1,9 & 1,9 \\
Pardas livres & 0,6 & 1,8 & 2,0 & 2,0 & 1,9 & 1,9 \\
Pretos livres & 0,7 & 0,7 & 0,9 & 1,0 & 1,2 & 1,4 \\
Pretas livres & 0,8 & 0,9 & 1,1 & 1,2 & 1,3 & 1,3 \\
Pardos escravos & 1,6 & 1,8 & 1,6 & 1,8 & 1,4 & 1,2 \\
Pardas escravas & 1,4 & 1,6 & 1,4 & 1,6 & 1,2 & 1,2 \\
Pretos escravos & 20,2 & 21,7 & 20,7 & 18,9 & 18,1 & 17,0 \\
Pretas escravas & 10,9 & 11,6 & 11,6 & 11,3 & 9,8 & 9,8 \\
\hline
\end{tabular}

Fonte: Mapas - 1791: AHU_ACL_CU_019, Cx.3, doc.252, rolo 3; 1798 e 1802: AHU, Conselho Ultramarino, Rio Grande do Sul, AHU_ACL_CU_019, Cx.7, doc. 485; 1805: AHU, Conselho Ultramarino, Rio Grande do Sul, AHU_ACL_CU_019, Cx.11, doc. 669; 1807 : Arquivo Nacional, Códice 808, v. 3; 1810: Arquivo Nacional, Códice 808, v. 3, folha 148.

TABELA 5

Taxas brutas de natalidade e mortalidade Capitania do Rio Grande de São Pedro - 1780-1810

\begin{tabular}{cccc}
\hline Anos & População & TBN (por mil) & TBM (por mil) \\
\hline 1780 & 20.309 & 48,1 & 25,4 \\
1791 & 25.034 & 50,3 & 29,7 \\
1798 & 33.286 & 52,3 & 21,0 \\
1802 & 39.115 & 43,4 & 21,6 \\
1805 & 43.008 & 46,5 & 29,4 \\
1807 & 46.581 & 48,1 & 25,4 \\
1810 & 52.226 & 50,8 & 25,4 \\
\hline
\end{tabular}

Fonte: Mapas - 1780: BNRJ, Seção de Manuscritos, 9, 4, 9 no 134; 1791: AHU_ACL_CU_019, Cx.3, doc.252, rolo 3; 1798 e 1802 : AHU, Conselho Ultramarino, Rio Grande do Sul, AHU_ACL_CU_019, Cx.7, doc. 485; 1805: AHU, Conselho Ultramarino, Rio Grande do Sul, AHU_ACL_CU_019, Cx.11, doc. 669; 1807: Arquivo Nacional, Códice 808, v. 3; 1810: Arquivo Nacional, Códice 808, v. 3, folha 148. 
TABELA 6

Taxas brutas de natalidade e mortalidade Diversas localidades do Brasil - 1775-1817

\begin{tabular}{llcc}
\hline Localidades & Ano & TBN (por mil) & TBM (por mil) \\
\hline Salvador, paróquia de Santo António & 1775 & & 35,1 \\
Salvador, paróquia da Penha & 1775 & & 33,9 \\
Salvador, paróquia do Passo & 1798 & & 34,5 \\
Pernambuco & 1775 & 41,4 & 32,8 \\
Espírito Santo & 1817 & 44,2 & 33,5 \\
\hline
\end{tabular}

Fonte: Dados reelaborados a partir de Schwartz (1988, p. 301, Tabela 43).

A comparação entre as taxas encontradas para o Rio Grande de São Pedro e para outras localidades brasileiras reforça a hipótese de que havia sub-registro de óbito infantil impactando na taxa bruta de mortalidade. Já em relação às taxas brutas de natalidade, o Rio Grande de São Pedro apresentou taxas um pouco mais elevadas, mas dentro do esperado para o período.

Na Tabela 7 apresentamos as taxas de crescimento anual da população da capitania do Rio Grande de São Pedro. Fica evidenciada a diferença entre cada freguesia e suas repartições. Acreditamos que as maiores taxas de crescimento ocorreram nas repartições das fronteiras do Rio Pardo e Rio Grande, devido à expansão em direção ao interior da capitania, com o desenvolvimento de atividades nessas áreas. No trabalho de Silmei S. Petiz (2009) pode ser encontrada a confirmação dessa hipótese - do desenvolvimento da região oeste, que foi fundamental para ocupação do território, objetivando fortalecer a presença da coroa portuguesa na região. Outro argumento que reforça o desenvolvimento econômico daquela área foi apontado por Helen Osório (2008), ao constatar o crescimento do rebanho vacum, de 1780 a 1791 , em $320 \%$; no período de 1790 a 1810 já se registravam proprietários com rebanhos de 4.000 a 15.000 cabeças. 0 número médio de escravos por plantel cresceu de 5,8 para 9,7 no mesmo período (1780-1810).

Da mesma forma, a autora demostra o aumento da distribuição de sesmarias: até a década de 1800 foram concedidas apenas 71 e, na década seguinte, 843 (OSÓRIO, 2008, p. 249-250).

De fato, em 1780 a população estava assim distribuída:

- 44,3\% na Vila de Porto Alegre, capital da capitania;

- 31,9\% na Fronteira do Rio Pardo;

- $23,8 \%$ na Fronteira do Rio Grande.

Três décadas depois a população deixou de se concentrar na região da capital da capitania, para se deslocar para o interior, em direção à fronteira, apresentando a seguinte proporção por distrito:

- $31,1 \%$ na Vila de Porto Alegre, capital da capitania;

- $38,5 \%$ na Fronteira do Rio Pardo;

- 30,5\% na Fronteira do Rio Grande. 
Em 1780, Porto Alegre, elevada à condição de capital da capitania, reunia o maior contingente populacional, distribuindo-se entre $71,5 \%$ de livres e $28,5 \%$ de cativos. Em 1798, a capital já apresentava mudanças importantes: além de perder a primazia na concentração populacional total, a própria composição alterou-se, aumentando o peso da população cativa, que passou para $36,7 \%$. No que diz respeito aos dados para 1810 , poucas mudanças foram observadas, como a maior concentração de habitantes na Fronteira do Rio Pardo e as proporções de cativos e livres quase nos mesmos patamares de 1780 ( $29,5 \%$ e $70,5 \%$, respectivamente).

Esses percentuais indicam que o Rio Grande de São Pedro, desde o final do século XVIII, contava com uma participação significativa do segmento cativo, que não difere de outras regiões da colônia, inclusive aquelas de ocupação mais antiga, como Bahia (cerca de $30 \%$ de cativos) e São Paulo (32\%), superando, por outro lado, áreas como Rio de Janeiro (26\%), Minas Gerais (26\%) e Pernambuco (26\%), conforme nos informa Helen Osório (2008).

De forma geral, acreditamos que os indicadores apresentados neste trabalho, além de auxiliarem no entendimento do desenvolvimento da população do Rio Grande de São Pedro, que deu origem ao estado do Rio Grande do Sul, podem servir de contraponto comparativo com outras regiões da América portuguesa, por meio do uso dessa mesma documentação, composta pelos mapas de população, levando em consideração os diferentes processos históricos e de ocupação territorial que marcaram cada uma delas.

0 estudo nos mostra que a população do Rio Grande de São Pedro, apesar de mais que dobrar em 30 anos, manteve sempre um contingente de escravos que estava por volta dos $30 \%$.

Os dados da Tabela 7 mostram a expansão em direção ao interior: a taxa de crescimento anual foi de 3,8\% para a fronteira do Rio Pardo e de 4,1\% para a fronteira do Rio Grande. Essas taxas podem ser entendidas dentro da lógica de se proteger o território português das incursões espanholas, o que se garantia pela ocupação de seus súditos. Esse movimento em direção ao interior também pode se sustentar devido à posição assumida por Rio Pardo, como importante entreposto comercial, estabelecendo a ligação com os extremos do território português. 0 cultivo de trigo, introduzido pelos açorianos, teve papel importante também nesse processo.

Conforme Aladrén (2012, p. 60), entre 1788 e 1800, houve o arranque inicial da economia escravista na região. São dessa época a instalação das primeiras charqueadas e a integração da capitania aos circuitos mercantis da América portuguesa por meio da exportação de couros, trigo e charque, gerando a demanda por mão de obra escrava. Ainda de acordo com esse autor, os três principais produtos comercializados (couro, charque e trigo) representavam, na década de 1790, 60\% do valor das exportações e, a partir de 1802 , entre $70 \%$ e $95 \%$ do total, sendo que o charque e o trigo destinavam-se quase que exclusivamente ao mercado interno (Rio de Janeiro, Bahia e Pernambuco) (ALADRÉN, 2012, p. 65). 
TABELA 7

População e taxa de crescimento médio anual, segundo repartições e freguesias Capitania do Rio Grande de São Pedro - 1780-1810

\begin{tabular}{|c|c|c|c|c|c|c|c|c|}
\hline \multirow{2}{*}{ Repartições e freguesias } & \multirow{2}{*}{$\begin{array}{l}\text { Cresc. } \\
\text { médio por } \\
\text { região (\%) }\end{array}$} & \multicolumn{7}{|c|}{ População } \\
\hline & & $1780(1)$ & $1791(2)$ & 1798 & 1802 & 1805 & 1807 & 1810 \\
\hline $\begin{array}{l}\text { Villa de Porto Alegre, capital da } \\
\text { capitania }\end{array}$ & \multirow[t]{7}{*}{2,0} & 8.992 & 9.883 & 11.543 & 13.629 & 14.749 & 15.116 & 16.224 \\
\hline $\begin{array}{l}\text { N. Sr. ․ M(enin)o de D(eu)s de Porto } \\
\text { Al(egr)e }\end{array}$ & & 1.713 & 2.349 & 3.438 & 4.183 & 4.286 & 4.940 & 5.531 \\
\hline N. Sr. da Conceição de Viamão & & 2.143 & 2.164 & 2.241 & 2.200 & 2.934 & 2.657 & 3.012 \\
\hline N. Sr. $\stackrel{a}{\text { dos Anjos }}$ & & 2.669 & 2.437 & 2.106 & 2.895 & 2.855 & 2.789 & 2.894 \\
\hline N. Sr. ${ }^{-a}$ da Conceição do Arroio & & 473 & 713 & 1.122 & 1.109 & 1.254 & 1.261 & 1.067 \\
\hline S(an)to António da Patrulha & & 1.347 & 1.525 & 1.849 & 2.342 & 2.483 & 2.491 & 2.667 \\
\hline N. Sr. $\stackrel{a}{\text { da }}$ Oliv(ei)ra da Vacaria & & 647 & 695 & 787 & 900 & 935 & 979 & 1.053 \\
\hline Fronteira do Rio Pardo & \multirow[t]{6}{*}{3,8} & 6.484 & 8.488 & 11.944 & 13.460 & 14.668 & 16.882 & 20.093 \\
\hline 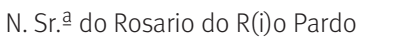 & & 2.690 & 3.211 & 4.130 & 3.983 & 5.450 & 7.388 & 7.006 \\
\hline N. Sr. da Conc(eiça)m da Caxoeira & & 750 & 1.507 & 2.778 & 3.498 & 3.263 & 3.168 & 6.553 \\
\hline S(e)n(ho)r Bom Jesus do Triunfo & & 1.447 & 2.027 & 3.018 & 3.234 & 3.305 & 3.408 & 3.224 \\
\hline Santo Amaro & & 816 & 880 & 1.002 & 1.769 & 1.422 & 1.664 & 1.752 \\
\hline São Jozé de Taquari & & 781 & 863 & 1.015 & 976 & 1.228 & 1.253 & 1.558 \\
\hline Fronteira do Rio Grande & \multirow[t]{4}{*}{4,1} & 4.833 & 6.664 & 9.800 & 12.026 & 13.592 & 14.583 & 15.909 \\
\hline São Pedro do Rio Grande & & 2.742 & 4.269 & 6.859 & 8.937 & 10.664 & 11.364 & 12.821 \\
\hline 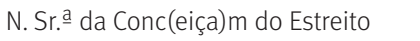 & & 1.421 & 1.561 & 1.822 & 1.825 & 1.901 & 1.956 & 1.647 \\
\hline São Luiz de Mostardas & & 670 & 834 & 1.119 & 1.264 & 1.027 & 1.263 & 1.441 \\
\hline Total da capitania & 3,2 & 20.309 & 25.034 & 33.286 & 39.115 & 43.008 & 46.581 & 52.226 \\
\hline \multirow[b]{2}{*}{ Repartições e freguesias } & \multirow{2}{*}{$\begin{array}{l}\text { Cresc. } \\
\text { médio por } \\
\text { região (\%) }\end{array}$} & \multicolumn{7}{|c|}{ Taxas de crescimento anual (\%) } \\
\hline & & $\begin{array}{c}1780- \\
1791\end{array}$ & $\begin{array}{l}1791- \\
1798\end{array}$ & $\begin{array}{l}1798- \\
1802\end{array}$ & $\begin{array}{l}1802- \\
1805\end{array}$ & $\begin{array}{l}1805- \\
1807\end{array}$ & $\begin{array}{l}1807- \\
1810\end{array}$ & $\begin{array}{c}1780- \\
1810\end{array}$ \\
\hline $\begin{array}{l}\text { Villa de Porto Alegre, capital da } \\
\text { capitania }\end{array}$ & \multirow[t]{7}{*}{2,0} & 0,9 & 2,2 & 4,2 & 2,7 & 1,2 & 2,4 & 2,0 \\
\hline $\begin{array}{l}\text { N. Sr. } \mathrm{a} \text { M(enin)o de D(eu)s de Porto } \\
\mathrm{Al}(\text { egr)e }\end{array}$ & & 2,9 & 5,6 & 5,0 & 0,8 & 7,4 & 3,8 & 4,0 \\
\hline N. Sr. ${ }^{a}$ da Conceição de Viamão & & 0,1 & 0,5 & $-0,5$ & 10,1 & $-4,8$ & 4,3 & 1,1 \\
\hline N. Sr. $\stackrel{a}{\text { dos Anjos }}$ & & $-0,8$ & $-2,1$ & 8,3 & $-0,5$ & $-1,2$ & 1,2 & 0,3 \\
\hline N. Sr. - da Conceição do Arroio & & 3,8 & 6,7 & $-0,3$ & 4,2 & 0,3 & $-5,4$ & 2,7 \\
\hline S(an)to António da Patrulha & & 1,1 & 2,8 & 6,1 & 2,0 & 0,1 & 2,3 & 2,3 \\
\hline N. Sr. - da Oliv(ei)ra da Vacaria & & 0,6 & 1,8 & 3,4 & 1,3 & 2,3 & 2,5 & 1,6 \\
\hline Fronteira do Rio Pardo & \multirow[t]{6}{*}{3,8} & 2,5 & 5,0 & 3,0 & 2,9 & 7,3 & 6,0 & 3,8 \\
\hline N. Sr. do Rosario do R(i)o Pardo & & 1,6 & 3,7 & $-0,9$ & 11,0 & 16,4 & $-1,8$ & 3,2 \\
\hline N. Sr. ${ }^{a}$ da Conc(eiça)m da Caxoeira & & 6,5 & 9,1 & 5,9 & $-2,3$ & $-1,5$ & 27,4 & 7,5 \\
\hline S(e)n(ho)r Bom Jesus do Triunfo & & 3,1 & 5,9 & 1,7 & 0,7 & 1,6 & $-1,8$ & 2,7 \\
\hline Santo Amaro & & 0,7 & 1,9 & 15,3 & $-7,0$ & 8,2 & 1,7 & 2,6 \\
\hline São Jozé de Taquari & & 0,9 & 2,3 & $-1,0$ & 8,0 & 1,0 & 7,5 & 2,3 \\
\hline Fronteira do Rio Grande & \multirow[t]{4}{*}{4,1} & 3,0 & 5,7 & 5,3 & 4,2 & 3,6 & 2,9 & 4,1 \\
\hline São Pedro do Rio Grande & & 4,1 & 7,0 & 6,8 & 6,1 & 3,2 & 4,1 & 5,3 \\
\hline N. Sr. da Conc(eiça)m do Estreito & & 0,9 & 2,2 & 0,0 & 1,4 & 1,4 & $-5,6$ & 0,5 \\
\hline São Luiz de Mostardas & & 2,0 & 4,3 & 3,1 & $-6,7$ & 10,9 & 4,5 & 2,6 \\
\hline \multicolumn{9}{|l|}{$\begin{array}{l}\text { Total população da região e média de } \\
\text { crescimento anual }\end{array}$} \\
\hline Total da capitania & 3,2 & 1,9 & 4,2 & 4,1 & 3,2 & 4,1 & 3,9 & 3,2 \\
\hline
\end{tabular}

Fonte: Mapas - 1780: BNRJ, Seção de Manuscritos, 9, 4, 9 no 134; 1791: AHU_ACL_CU_019, Cx.3, doc.252, rolo 3; 1798 e 1802: AHU, Conselho Ultramarino, Rio Grande do Sul, AHU_ACL_CU_019, Cx.7, doc. 485; 1805: AHU, Conselho Ultramarino, Rio Grande do Sul, AHU_ACL_CU_019, Cx.11, doc. 669; 1807: Arquivo Nacional, Códice 808, v. 3; 1810: Arquivo Nacional, Códice 808, v. 3, folha 148 .

(1) Total ajustado conforme índice proposto por Alden (1963).

(2) Distribuição por freguesia estimado com base na média entre os mapas de 1780 e 1798. 
Portanto, os resultados apresentados pela análise dos mapas de população entre 1780 e 1810 refletem essa conjuntura de expansão econômica e o aumento da população, que passou a ser distribuída em direção às fronteiras do Rio Grande e de Rio Pardo. Em que pese o fato de a população passar de 20.309 pessoas, em 1780 , para 52.226 , em 1810 , a composição entre livres e escravos pouco mudou em termos proporcionais, com a população cativa representando em torno de $30 \%$ do total. Já a razão de sexo mostrou uma desigualdade entre os livres e os escravos, o que era esperado considerando-se a necessidade das sociedades escravistas, em que a participação do escravo do sexo masculino se sobrepõe.

Finalizando, a exploração dos mapas de população permite visualizar um perfil da população para aquele período. Mais do que isso, possibilita análises comparativas não só em termos das diversidades internas da capitania, mas também com outras regiões da América portuguesa. Apesar de reconhecermos a necessidade de ajustes, trata-se de uma fonte muito rica e que merece a atenção dos estudiosos da demografia histórica brasileira.

\section{Referências}

ALADRÉN, G. Sem respeitar fé nem tratados: escravidão e guerra na formação histórica da fronteira sul do Brasil (Rio Grande de São Pedro, c. 1777-1835). Tese (Doutorado em História) Universidade Federal Fluminense - UFF, Rio de Janeiro, 2012.

ALDEN, D. Population of Brazil in the late eighteenth century: a preliminary study. The Hispanic American Historical Review, v. 43, n. 2, p. 173-205, May 1963.

BERUTE, G. S. Atividades mercantis do Rio Grande de São Pedro: negócios, mercadorias e agentes mercantis (1808-1850). Tese (Doutorado em História) - Programa de Pós-graduação em História, Universidade Federal do Rio Grande do Sul - UFRGS, Porto Alegre, 2011.

ESPÍRITO SANTO, M. F. Fundamentos da incorporação do Rio Grande do Sul ao Brasil e ao espaço português. In: BOEIRA, N.; GOLIN, T. (Org.). História geral do Rio Grande do Sul - Colônia. Passo Fundo: Méritos, v. 1, 2006. p. 23-42.

FIALHO, D. M. A Porto Alegre de Antônio Eleuthério de Camargo. In: I SIMPÓSIO BRASILEIRO DE CARTOGRAFIA HISTÓRICA. Anais... Parati/RJ: Centro de Referência em Cartografia Histórica da Universidade de Minas Gerais - UFMG, maio 2011. Disponível em: 〈http://www.ufmg.br/ rededemuseus/crch/simposio/FIALHO_DANIELA_M.pdf〉. Acesso em: 20 jul. 2011.

GRAEBIN, C. M. G. Vida cotidiana dos açorianos pelas freguesias e caminhos. In: BOEIRA, N.; GOLIN, N. (Org.). História geral do Rio Grande do Sul - Colônia. Passo Fundo: Méritos, v. 1, 2006. p. 203-223.

MARCÍLIO, M. L. Crescimento demográfico e evolução agrária paulista 1700-1836. São Paulo: Editora Hucitec/Edusp, 2000.

MATOS, P. T.; SCOTT, A. S. V.; SCOTT, D. Counting colonial populations in the Portuguese America, 1760 - 1820: between central impositions and local constrains. In: INTERNATIONAL SEMINAR ON REGISTERING AND COUNTING THE POPULATION: THE PRODUCTION AND EXPLORATION OF CENSUS INFORMATION FROM EARLY MODERN TIMES TO THE END OF 20TH CENTURY. Anais... Campinas: IUSSP, Nepo/Unicamp, maio 2016.

MATOS, P. T.; SOUSA, P. S. A estatística da população na América portuguesa, 1750-1820. Memorias - Revista Digital de Historia y Arqueología desde el Caribe, n. 25, 2015. 
NADALIN, S. O. História e demografia: elementos para um diálogo. Campinas: Abep, 2004.

A população no passado colonial brasileiro: mobilidade versus estabilidade. Topoi, v. 4, n. 7, p. 222-275, 2003.

OSÓRIO, H. Expansão territorial e população: a capitania do Rio Grande no primeiro quartel do século XIX. In: SCOTT, A. S. V.; FLECK, E. C. D. A corte no Brasil: população e sociedade no Brasil e em Portugal no início do século XIX. São Leopoldo: Oikos; Editora da Unisinos, 2008. p. 235-252.

. O império português no sul da América: estancieiros, lavradores e comerciantes. Porto Alegre: Editora da UFRGS, 2007.

PETIZ, S. Caminhos cruzados: famílias e estratégias escravas na fronteira oeste do Rio Grande de São Pedro. Tese (Doutorado em História) - Programa de Pós-graduação em História, Universidade do Vale do Rio dos Sinos - Unisinos, 2009.

SANTOS, C. M. Importância da capitania do Rio Grande para o Brasil. In: BOEIRA, N.; GOLIN, T. (Org.). História geral do Rio Grande do Sul - Colônia. Passo Fundo: Méritos, v. 1, 2006. p. 65-84.

SCHWARTZ, S. B. Segredos internos. Engenhos e escravos na sociedade colonial. São Paulo: Companhia das Letras, 1988.

SCOTT, A. S. V.; SCOTT, D. Uma alternativa metodológica para o cruzamento semiautomático de fontes nominativas: o NACAOB como opção para o caso luso-brasileiro. In: BOTELHO, T. R.; VAN LEEUWEN, M. H. D. (Org.). História social: perspectivas metodológicas. Belo Horizonte: Veredas \& Cenários, 2012. p. 83-108.

SCOTT, A.; BERUTE, G. S.; SCOTT, D.; SILVA, J. F.; FREITAS, D. T. L. Counting colonial populations: a comparative exercise between ecclesiastical and civil sources from the southernmost region of Portuguese America in the late colonial period. Anais de História de Além-Mar, n. XVI, p. 281-312, 2015 (Dossiê: The Demography of the Portuguese Empire. Sources, methods and results, 1776-1822).

\section{Sobre o autor}

Dario Scott é doutorando em Demografia no Núcleo de Estudos de População "Elza Berquó" da Universidade Estadual de Campinas (Nepo/Unicamp) e mestre em Computação Aplicada pela Universidade do Vale do Rio dos Sinos (Unisinos).

\section{Endereço para correspondência}

Alameda Carlos Barduchi, Lote 12 - Dois Córregos

13278-170 - Valinhos-SP, Brasil

\section{Abstract}

The population of Rio Grande de São Pedro according to population maps from 1780 to 1810

The aim of this article is to present the results of a methodological exercise exploring potentials and limitations of population maps related to Rio Grande de São Pedro, between the late eighteenth and early nineteenth centuries. This documentation, produced at request of the Portuguese crown, was prepared for several captaincies and included, in charts or tables, 
information on the population based on sex, legal status, age and color/ethnicity. In the case of Rio Grande de São Pedro, seven of these "maps" are available and from their analysis, it is possible to know the general characteristics of the population of Rio Grande de São Pedro, a captaincy located in the extreme south of Portuguese America. In this regard, upon a general characterization of the documentation used, demographic indicators of the population in that territory in the passage from the eighteenth century to the nineteenth century were established, through statistics produced for the years 1780, 1791, 1798, 1808, 1805, 1807 and 1810. The most significant results include a clear predominance of white population, sex ratio imbalance, especially among the slave population, and a variation in the weight of population distribution by territory, which shows occupation towards the border areas.

Keywords: Colonial population. Demographic sources. Historical demography.

\section{Resumen}

La población de Rio Grande de São Pedro según los mapas poblacionales de 1780 a 1810

El objetivo de este artículo es presentar los resultados de un ejercicio metodológico que explora las potencialidades y los límites de los mapas de población relativos a Rio Grande de São Pedro entre finales del siglo XVIII y principios del XIX. Esta documentación, producida a demanda de la corona portuguesa, fue elaborada para diversas capitanías e incluía, en formato de cuadro o tabla, informaciones sobre la población en relación con sexo, condición jurídica, edad, color/etnia. En el caso de Rio Grande de São Pedro están disponibles siete de esos «mapas» y, a partir de su análisis, es posible conocer las características generales de la población de esta capitanía, situada en el extremo sur de la América portuguesa. En ese sentido, a partir de una caracterización general de la documentación utilizada se buscó establecer indicadores demográficos de la población en aquel territorio en el pasaje del siglo XVIII hacia el XIX, a través de las estadísticas producidas para los años 1780, 1791, 1798, 1808, 1805, 1807 y 1810. Entre los resultados, se destaca el predominio de la población blanca, el desequilibrio en la razón de los sexos, especialmente entre la población esclava, y la variación del peso de la distribución de la población en el territorio, con mayor ocupación hacia las regiones fronterizas.

Palabras clave: Población colonial. Fuentes demográficas. Demografía histórica. 
